\title{
AN APPARATUS FOR KEEPING WARM A BASIN OF SALINE SOLUTION
}

\author{
A. L. MACKEEN, R.N.
}

\section{Roxbury, Massachusetts}

The apparatus illustrated by the accompanying photographs was found very useful in the operating room for keeping a basin of saline solution hot during an operation.

A plunger stand, such as has been used for arms, was chosen and the plunger removed. Then to one of the iron rods at the side was attached an iron ring, such as is used in a laboratory to hold flasks over a gas jet. This was clamped at the proper height to hold a small electric stove, one with legs preferred, which should set firmly on the iron ring. The electric cord may be dropped through the stand to the floor and then connected with a wall socket, so that it will not be in the sterile field of operation. It should be of sufficient length to allow the stand to be moved where needed.

When the sterile nurse is ready, she can drape a wet, sterile towel around the stand and then set a sterile basin in the ring, so that the bottom rests on top of the stove. If the solution is hot when poured into the basin, it will keep the proper temperature on the medium heat.
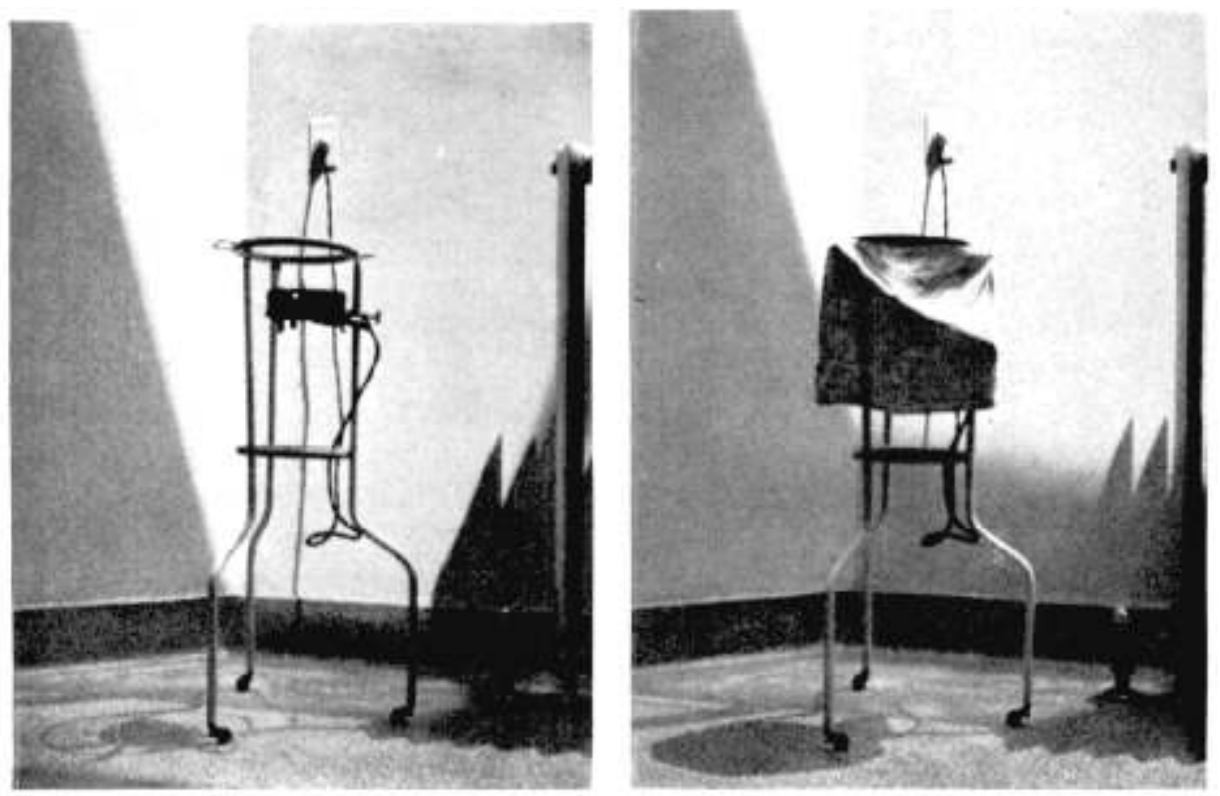